3. De Marchis E, Knox M, Hessler D, et al. Physician burnout and higher clinic capacity to address patients' social needs. J Am Board Fam Med 2019;32:69-78.

4. Thornton RL, Glover CM, Cené CW, Glik DC, Henderson JA, Williams DR. Evaluating strategies for reducing health disparities by addressing the social determinants of health. Health Aff (Millwood) 2016;35:1416-23.

doi: 10.3122/jabfm.2019.05.190122

The above letter was referred to the author of the article in question, who offers the following reply.

\section{Response: Re: Physician Burnout and Higher Clinic Capacity to Address Patients' Social Needs}

To the Editor: We thank Ingerick and Iuga for their interest in our work on provider burnout. ${ }^{1}$ Our findings suggested that family physicians working in clinical settings equipped to address patients' social risk factors had lower odds of reporting burnout symptoms. The results highlight an underexplored rationale for bolstering clinic-based social services: these services may decrease clinician burnout. Clinic-level strategies to collect and respond to social risk dataand the multi-level impacts of these strategies-should be the focus of future research.

Emilia H. De Marchis, MD, MAS Department of Family \& Community Medicine, University of California-San Francisco, San Francisco, CA emilia.demarchis@ucsf.edu

Danielle Hessler, PhD

Laura M. Gottlieb, MD, MPH

To see this article online, please go to: http://jabfm.org/content/ 32/5/000.full.

\section{Reference}

1. De Marchis EH, Knox M, Hessler D, et al. Perceived clinic capacity to address patients' social needs and family physician burnout. J Am Board Fam Med 2018;32:69-78.

Funding Statement: This publication was supported by a fellowship training grant by the National Research Service Award (NRSA) T32HP19025. Its contents are solely the responsibility of the authors and do not represent the official views of NRSA.

doi: 10.3122/jabfm.2019.05.190219

\section{Re: Signs and Symptoms That Rule Out Community-Acquired Pneumonia in Outpatient Adults: A Systematic Review and Meta-Analysis}

To the Editor: Dr. Marchello et $\mathrm{al}^{1}$ make an important contribution to clinical medicine and patient care by creating evidence for how to combine key clinical findings to confidently position the possibility of pneumonia in adults further down in the differential diagnosis in patients with acute respiratory illness. Although their findings seem to ring true from clinical experience, their clinical tool requires prospective validation per the authors.

While most family physicians currently do not have point-of-care ultrasound (POCUS), the majority will in the future. Use of pocket ultrasound is becoming common among medical students, training in family medicine residencies is increasing, and POCUS continued medical education training is very accessible. Point-ofcare lung ultrasound (POCLUS) is more reliable than a chest radiograph to rule in or rule out pneumonia in adults and children. 2,3,4,5 The author's suggested future prospective research might also include a research arm to evaluate the potential additive benefit of combining POCLUS with their clinical decision-making tool.

Respectfully submitted,

Louis A. Kazal, Jr., MD, FAAFP

Associate Professor, Department of Community and Family Medicine, Geisel School of Medicine at Dartmouth, Hanover, New Hampshire louis.a.kazal@dartmouth.edu

To see this article online, please go to: http://jabfm.org/content/ 32/5/000. full.

\section{References}

1. Marchello CS, Ebell MH, Dale AP, Harvill ET, Shen Y, Whalen CS. Signs and symptoms that rule out communityacquired pneumonia in outpatient adults: a systematic review and meta-analysis. J Am Board Fam Med March 2019;32: 234-247.

2. Kaysin A, Viera AJ. Adults: diagnosis and management. Am Fam Physician 2016;94:698-706.

3. Ye X, Xiao H, Chen B, Zhang S. Accuracy of lung ultrasonography versus chest radiography for the diagnosis of adult community-acquired pneumonia: review of the literature and meta-analysis. PLoS One 2015;10:e130066.

4. Chavez MA, Shams N, Ellington LE, et al. Lung ultrasound for the diagnosis of pneumonia in adults: a systematic review and meta-analysis. Respir Res 2014;15:50.

5. Samson F, Gorostiza I, González A, Landa M, Ruiz L, Grau M. Prospective evaluation of clinical lung ultrasonography in the diagnosis of community-acquired pneumonia in a pediatric emergency department. Eur J Emerg Med. 2018;25:65-70.

doi: 10.3122/jabfm.2019.05.190132

The above letter was referred to the author of the article in question, who offers the following reply.

\section{Response: Re: Signs and Symptoms That Rule Out Community-Acquired Pneumonia in Outpatient Adults: A Systematic Review and Meta-Analysis}

To the Editor: We thank Dr. Kazal for the comment on our publication "Signs and Symptoms That Rule out Community-Acquired Pneumonia in Outpatient Adults: A Systematic Review and Meta-Analysis."1 Not only is lung ultrasonography a possible alternative to chest radiography (CXR) for the diagnosis of community-acquired pneumo- 
nia $(\mathrm{CAP})^{2,3}$ but also they can be useful for the differential diagnosis of chest pain and dyspnea in the emergency department. $^{4,5}$ We agree that point-of-care ultrasound (POCUS) should be explored in future studies on clinical decision rules for CAP, in addition to other point-of-care (POC) tests such as c-reactive protein.

However, POCUS is not yet ubiquitous nor has it replaced CXR as the current reference standard for diagnosing CAP. We express caution about the broad use of POCUS, as it suffers from subjective interpretation where interrater reliability varies ${ }^{6}$ and should be limited to clinicians with sufficient training and adequate patient volume. ${ }^{7}$ Most previous studies have been done in the emergency department or inpatient settings where there is a higher volume; whether primary care clinicians can duplicate that accuracy with lower volume requires further study. In addition, because pneumonia is relatively rare in primary care patients (about $3 \%$ to $4 \%$ of patients with lower respiratory tract symptoms), even a fairly accurate test can have a poor positive predictive value, leading to antibiotic overuse. We, therefore, advocate that future studies focus on the integration of simple heuristics, the overall clinical impression, ${ }^{8}$ validated clinical decision rules, and validated POC tests (eg, c-reactive protein $)^{9}$ to identify patients at very low risk of CAP in the outpatient setting, as well as those who may benefit for further diagnostic testing, whether it be CXR or POCUS.

Christian S. Marchello, PhD, MT(ASCP) Center for International Health, University of Otago, Dunedin, New Zealand christian.marchello@otago.ac.nz Mark H. Ebell, MD, MS

To see this article online, please go to: http://jabfm.org/content/ 32/5/000.full.

\section{References}

1. Marchello CS, Ebell MH, Dale AP, Harvill ET, Shen Y, Whalen CC. Signs and symptoms that rule out communityacquired pneumonia in outpatient adults: a systematic review and meta-analysis. J Am Board Fam Med 2019;32:234-47.

2. Pereda MA, Chavez MA, Hooper-Miele CC, et al. Lung ultrasound for the diagnosis of pneumonia in children: a meta-analysis. Pediatrics 2015;135:714-22.

3. Chavez MA, Shams N, Ellington LE, et al. Lung ultrasound for the diagnosis of pneumonia in adults: a systematic review and meta-analysis. Respir Res 2014;15:50.

4. Buhumaid RE, St-Cyr Bourque J, Shokoohi H, Ma IWY, Longacre M, Liteplo AS. Integrating point-of-care ultrasound in the ED evaluation of patients presenting with chest pain and shortness of breath. Am J Emerg Med 2019;37:298 303.

5. Zanobetti M, Scorpiniti M, Gigli C, et al. Point-of-care ultrasonography for evaluation of acute dyspnea in the ED. Chest 2017;151:1295-301.

6. Gravel CA, Monuteaux MC, Levy JA, Miller AF, Vieira RL, Bachur RG. Interrater reliability of pediatric point-of-care lung ultrasound findings. Am J Emerg Med. In press.

7. Ebell M. Point-of-care ultrasonography: an effective tool when used appropriately. Am Fam Physician 2019;99:143.
8. Dale AP, Marchello CS, Ebell MH. Clinical gestalt to diagnose pneumonia, sinusitis, and pharyngitis: a meta-analysis. Br J Gen Pract. In press.

9. van Vugt SF, Broekhuizen BD, Lammens C, et al. Use of serum $\mathrm{C}$ reactive protein and procalcitonin concentrations in addition to symptoms and signs to predict pneumonia in patients presenting to primary care with acute cough: diagnostic study. BMJ 2013;346:f2450.

doi: $10.3122 /$ jabfm.2019.05.190231

\section{Re: Timely Outpatient Follow-Up Is Associated with Fewer Hospital Readmissions Among Patients with Behavioral Health Conditions}

To the Editor: I commend Dr Nadareh Pourat and colleagues $^{1}$ for their important work on timely outpatient follow-up and hospital readmissions among patients with behavioral health conditions. I do, however, have a few concerns.

First, the concept of trust in the doctor-patient relationship is an essential one that affects clinical outcomes, ${ }^{2}$ while distrust has been associated with treatment discordance. ${ }^{3}$ Thus, patients that were dissatisfied with the inpatient care during the index admission may not be predisposed to attend follow-up or comply with treatment. It would have been informative if their regression models accounted for patient's trust in their health care providers and how it may affect compliance with followup, especially in this patient population.

Second, although the authors admirably adjusted for many confounders in their regression models, I wonder if Pourat and colleagues ${ }^{1}$ considered controlling for anxiety or homelessness/unstable housing, both of which are drivers of hospitalization and readmissions. ${ }^{4,5}$ It may be interesting and revealing to assess compliance with follow-ups in homeless individuals with behavioral health conditions, such as anxiety disorders, and how both factors might affect timely follow-up outpatient visits.

Ayodeji Otufowora, MB, BS, MPH, CPH

Department of Epidemiology, College of Public Health and Health Professions and College of Medicine, University of Florida, Gainesville, FL deji.otufowora@ufl.edu

The author is thankful to his research mentor Dr. Linda Cottler for her support.

To see this article online, please go to: http://jabfm.org/content/ 32/5/000. full.

\section{References}

1. Pourat N, Chen X, Wu S-H, Davis AC. Timely outpatient follow-up is associated with fewer hospital readmissions among patients with behavioral health conditions. J Am Board Fam Med. 2019;32:353-61.

2. Birkhäuer J, Gaab J, Kossowsky J, et al. Trust in the health care professional and health outcome: a meta-analysis. PLoS One. 2017;12:e0170988. 